Report

\title{
Validation of a tissue microarray to study differential protein expression in inflammatory and non-inflammatory breast cancer
}

\author{
G.G. Van den Eynden ${ }^{1,2}$, I. Van der Auwera ${ }^{1,2}$, S. Van Laere ${ }^{1,2}$, C.G. Colpaert $^{1,2}$, P. van \\ $\operatorname{Dam}^{1,2}$, S. Merajver ${ }^{3}$, C.G. Kleer ${ }^{4}$, A.L. Harris ${ }^{5}$, E.A. Van Marck $^{1,2}$, L.Y. Dirix ${ }^{1,2}$, and \\ P.B. Vermeulen ${ }^{1,2}$ \\ ${ }^{1}$ Translational Cancer Research Group, Laboratory of Pathology, University Hospital Antwerp, University of \\ Antwerp, Edegem; ${ }^{2}$ Translational Cancer Research Group, Oncology Centre, General Hospital Sint-Augustinus, \\ Wilrijk, Belgium; ${ }^{3}$ Department of Internal Medicine, University of Michigan; ${ }^{4}$ Department of Pathology, \\ University of Michigan Comprehensive Cancer Center, Ann Arbor, MI, USA; ${ }^{5}$ Cancer Research UK Growth Factor \\ Group, Weatherall Institute of Molecular Medicine, John Radcliffe Hospital, Oxford, UK
}

Key words: carbonic anhydrase IX, differential protein expression, E-Cadherin, epidermal growth factor receptor, estrogen receptor, HER2/neu, immunohistochemistry, inflammatory breast cancer, P53, progesterone receptor, RhoC GTPase, tissue microarray

\section{Summary}

Aims. Inflammatory breast cancer (IBC) is an aggressive subtype of breast cancer with poor prognosis. The mechanisms responsible for the aggressive clinical evolution are incompletely understood. We constructed a tissue microarray (TMA) and validated its use in translational IBC research. Differential expression of proteins that might play a role in causing the IBC phenotype was studied.

Methods and results. A TMA containing 34 IBC and 41 non-stage matched non-IBC tumours was constructed. Five core biopsies were taken for each IBC and three cores for each non-IBC tumour. The TMA was validated using three approaches: (1) the excellent concordance between immunohistochemical results of the initial pathological examination and the results obtained with the TMA for ER, PR and HER2/neu $(\kappa>0.74)$; (2) the known differential expression between IBC and non-IBC for four bio-markers in IBC (ER, PR, p53 and HER2/neu) was confirmed $(p<0.01)$; (3) the HER2/neu status using three different antibodies (CB11, TAB250 and HercepTest) was highly concordant $(\kappa>0.75)$. Furthermore, the overexpression of E-Cadherin and RhoC GTPase in IBC $(p<0.05)$ was confirmed. We did not find a differential expression pattern for carbonic anhydrase IX (CA IX) and EGFR.

Conclusions. Using different approaches, we have validated the use of our TMA for studying differential protein expression in IBC and non-IBC. We confirm the overexpression of E-Cadherin and RhoC GTPase in IBC. The lack of differential expression for CA IX and EGFR might suggest the pathways are equally utilised in both types of breast cancer.

\section{Introduction}

Inflammatory breast cancer (IBC) is a well-defined clinical and pathological subtype of breast cancer, comprising up to $5 \%$ of all breast malignancies [1]. Although major improvement in the treatment was made with the introduction of a multi-modality approach, the overall prognosis remains poor [2, 3]. The biological behaviour of IBC is one of more local aggressive growth, rapid haematogenous and lymphatic invasion and as such is very different from other high-grade invasive breast carcinomas, explaining the number of involved lymph nodes and even distant metastases at the time of diagnosis $[1,4]$. Although validated biomarkers of worse prognosis in breast cancer, such as increased proliferation fraction, the HER2/neu amplification and the absence of steroid hormone receptors are found in IBC [3, 5-11], these clearly fail to explain the typical clinical course of patients suffering from IBC. Little is known about the underlying 
mechanisms of the rapid progression, strong angiogenesis and (lymph)angioinvasiveness and the question remains whether and to what extent tumoural and/or stromal factors are responsible for the specific IBC phenotype. Better understanding of the IBC phenotype can not only lead to new prognostic markers but might also suggest specific therapeutic targets for IBC. Considering IBC as a unique human model of early metastasis, these studies might also provide better insight in tumour metastasis and tumour-stroma interactions.

Most studies investigating specific molecules for their eventual contribution to the IBC phenotype, started from tumour cell lines and animal model observations [12-14]. The authors confirmed their findings on human material using immunohistochemical (IHC) analyses of whole tissue sections with antibodies directed against molecules thought to be key players in the IBC phenotype $[15,16]$. Using whole tissue section analysis too, others investigated the role in IBC of molecules known to be pivotal in cancer progression and metastasis $[15,17]$. With these time-consuming and labour-intensive techniques, the involvement of RhoC GTPase and E-Cadherin in the IBC phenotype has been demonstrated.

With the introduction of molecular biological techniques such as gene microarray analysis and quantitative RT-PCR, the number of genes known to be involved in tumourigenesis, cancer progression and metastasis has dramatically increased. Using these techniques, RNA expression data of thousands of genes can be gathered in a limited number of tumours. In the near future, we expect that these techniques will reveal a large number of molecules involved in the IBC phenotype. Differential RNA expression of these candidate molecules has to be validated at the protein level on large data sets. Therefore, in response to the dramatic increase in new candidate bio-markers, Sauter et al. developed the tissue microarray (TMA) technique [18-20]. Using this technique, the protein expression of hundreds of tumours can be evaluated on one slide under standardised conditions. TMA technology has, to the best of our knowledge, never been applied in IBC studies. Knowing the specific biology and growth pattern of IBC, general concerns about using TMA technology such as sampling-bias and tissue loss, have to be carefully considered and investigated.

The aim of this study is the implementation of the TMA technique in the translational IBC research. We have investigated methodological problems and validated the use of our TMA for studying differential protein expression in IBC. Furthermore, we studied the differential protein expression of less investigated molecules in IBC, which could be playing a role in this unique breast cancer phenotype.

\section{Materials and methods}

\section{Construction of TMA}

Using the Beecher Instruments Tissue Arrayer (Beecher Instruments, Silver Springs, MD, USA) an IBC TMA was constructed. Thirty-four consecutive IBC patients and 41 control non-stage matched breast cancer patients were included in this study. All IBC patients presented with a recently ( $\leq 8$ weeks, median $\leq 5$ weeks) developed diffuse enlargement of the breast with redness and oedema of more than $1 / 3 \mathrm{rd}$ of the skin of the breast. This IBC population was previously described [17]. The average age of the IBC patients was 56 years (range: $25-83$ years).

The non-IBC control population consisted of 16 $\mathrm{T} 1$, nine $\mathrm{T} 2,10 \mathrm{~T} 3$ and six $\mathrm{T} 4 \mathrm{a}$ breast cancer patients. Average age of the control population was 58 years (range 32-80 years). The TMA was planned to contain five and three core biopsies for every IBC and nonIBC tumour, respectively. Figure 1 shows the TMA as it was planned at the beginning of this study. The TMA can be divided into two parts. Columns 1 and 2 contain five core biopsies of 26 and eight IBC tumours respectively. Column 3 contains three core biopsies of $16 \mathrm{~T} 1$ and nine T2 tumours, column 4 contains three core biopsies of $10 \mathrm{~T} 3$ and six T4 tumours.

\section{IHC staining}

Five micrometer slides were cut from the TMA and immunohistochemical (IHC) staining was performed for the following antigens: estrogen receptor (ER), progesterone receptor (PR), p53, E-Cadherin, HER2/neu, Carbonic anhydrase IX (CA IX), epidermal growth factor receptor (EGFR) and RhoC GTPase (RhoC). IHC for the HER2/neu antigen was done using three different antibodies (CB11, TAB250 and HercepTest). Table 1 shows the antigens IHC analysis was performed for on this TMA, mentioning the primary antibody, the pre-treatment and the detection system used.

\section{Validation}

To validate our TMA for studying differential protein expression in IBC, three aspects were studied. 


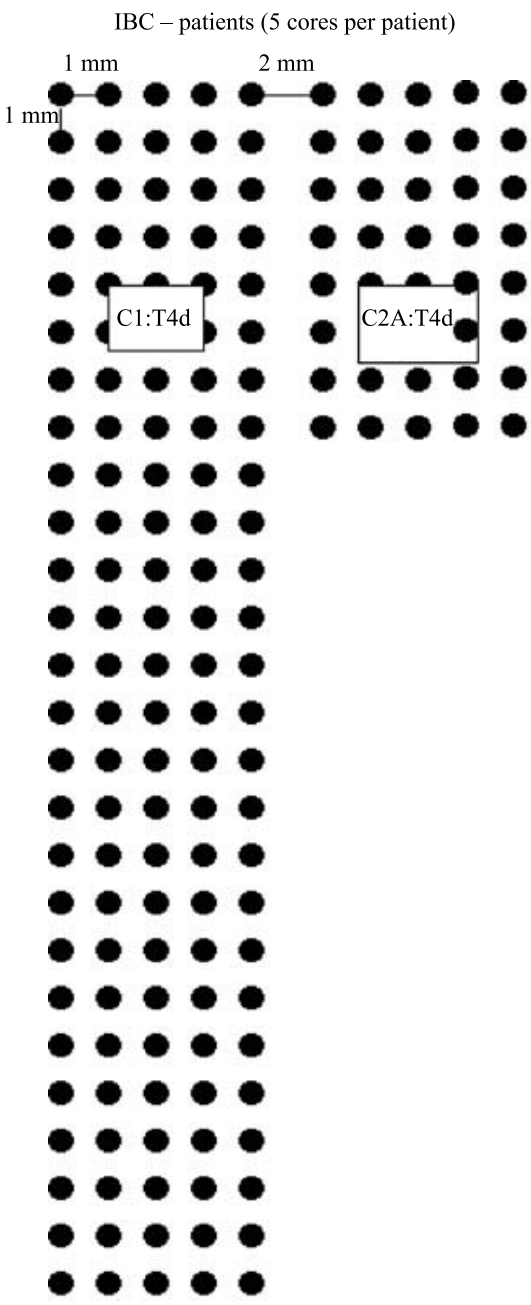

Column 1

Column 2

Non-IBC - patients (3 cores per patient)
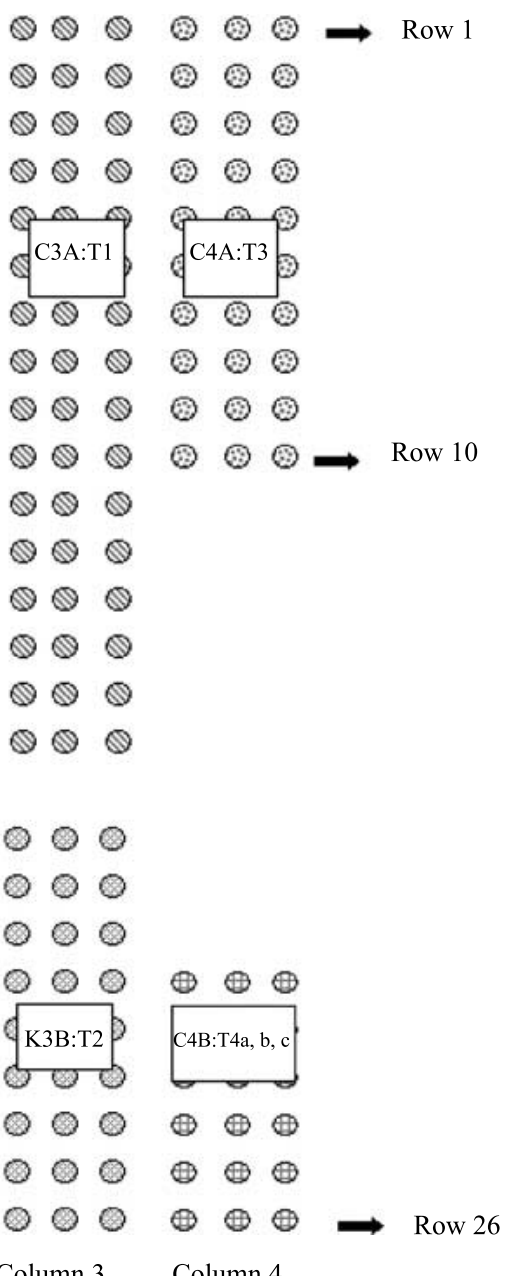

Figure 1. TMA of IBC as planned at the beginning of this study. It consists of four columns and 26 rows. Column 1 (C1) and 2 (C2) contain five core biopsies from 26 and eight IBC tumours, respectively. Column 3 (C3) and four (C4) contain 41 non-stage matched non-IBC tumours, divided into four groups: Column 3A (C3A) contains 16 T1 breast tumours, Column 3B (C3B) contains nine T2 breast tumours, Column 4A (C4A) contains $10 \mathrm{~T} 3$ breast tumours and Column 4B (C4B) contains six T4 breast tumours.

\section{Concordance between results of the pathology} report and the TMA results

Whole tissue section IHC analysis for the ER, PR, p53 and HER2/neu antigen as described in the pathology report were reviewed (PV and $\mathrm{GVdE}$ ), if original IHC slides were available. These results were compared to the IHC results for these bio-markers using our TMA. For interpretation of the IHC reactivity, the mean score of all available core biopsies per patient was calculated. For ER and PR, the percentage of tumour cells with nuclear immunoreactivity was scored on a 0-4 scale $(0=0 \%$ positive tumour cells, $1=1-9 \%$ positive tumour cells, $2=10-49 \%$ positive tumour cells, $3=50-99 \%$ positive tumour cells, $4=100 \%$ positive tumour cells). Furthermore, ER and PR status were determined based on this score: Score 0-1 was considered ER or PR negative, score 2-4 was considered ER or PR positive.

For the p53 antigen, a patient was considered p53 positive when more than $10 \%$ of tumour cells showed nuclear immunoreactivity.

The HER2/neu score using the HercepTest (DakoCytomation, Glostrup, Denmark) was interpreted on a $0-3$ score $(0=$ no staining or membranous staining in less than $10 \%$ of tumour cells; $1=$ faint or barely perceptible partial membranous staining in more than $10 \%$ of tumour cells; $2=$ weak to complete membranous staining in more than $10 \%$ of tumour 
Table 1. Antigens IHC analysis was performed for on this TMA, mentioning the primary antibody (clone, producer, dilution, incubation time), pre-treatment and detection system used

\begin{tabular}{|c|c|c|c|}
\hline Antigen & $\begin{array}{l}\text { Primary antibody (clone, producer } \\
\text { dilution, incubation time) }\end{array}$ & Pre-treatment & $\begin{array}{l}\text { Detection system } \\
\text { (producer) }\end{array}$ \\
\hline ER & $\begin{array}{l}\text { 6F11, Novocastra, Newcastle, UK } \\
\qquad(1 / 25,1 \mathrm{~h})\end{array}$ & $\begin{array}{l}\mathrm{WWB}^{\mathrm{b}} \\
\left(98^{\circ} \mathrm{C}\right)\end{array}$ & StreptABC ${ }^{\mathrm{d}}$ \\
\hline PR & $\begin{array}{l}\text { 16, Novocastra, Newcastle, UK } \\
(1 / 300,1 \mathrm{~h})\end{array}$ & $\begin{array}{l}\text { citrate buffer } \\
\text { (30 min) }\end{array}$ & \\
\hline p53 & $\begin{array}{l}\text { D0-7, Novocastra, Newcastle, UK } \\
\quad(1 / 300,30 \mathrm{~min})\end{array}$ & & $\mathrm{LSAB}^{\mathrm{d}}$ \\
\hline E-Cadherin & $\begin{array}{l}\text { HECD-1, Takara, Kyoto, Japan } \\
\qquad(1 / 80,1 \mathrm{~h})\end{array}$ & & StreptABC ${ }^{\mathrm{d}}$ \\
\hline HER2/neu & CB11, Novocastra, Newcastle, UK & None & \\
\hline HER2/neu & $\begin{array}{l}\text { TAB250, Zymed, San Francisco, CA, USA } \\
\quad(1 / 50,1 \mathrm{~h})\end{array}$ & & \\
\hline CA IX & $\begin{array}{l}\text { Antibody kindly provided by Prof } \\
\text { Dr A. Harris }(1 / 50,1 \mathrm{~h})\end{array}$ & & EnVision $^{\mathrm{d}}$ \\
\hline HER2/neu & HercepTest ${ }^{\mathrm{d}}$ & & \\
\hline $\mathrm{EGFR}^{\mathrm{a}}$ & EGFR PharmDx kit ${ }^{\mathrm{d}}$ & & \\
\hline RhoC GTPase & $\begin{array}{l}\text { Antibody kindly provided by } \\
\text { Prof Dr C.G. Kleer }(1 / 750,1 \mathrm{~h})\end{array}$ & $\begin{array}{l}\mathrm{WWB}^{\mathrm{b}}\left(98^{\circ} \mathrm{C}\right) \\
\operatorname{ARS}^{\mathrm{c}}(30 \mathrm{~min})\end{array}$ & EnVision $^{\mathrm{d}}$ \\
\hline
\end{tabular}

${ }^{\mathrm{a}}$ EGFR.

${ }^{\mathrm{b}}$ Warm water bath.

c Antigen retrieval solution high pH (DakoCytomation, Glostrup, Denmark).

d DakoCytomation, Glostrup, Denmark.

cells; $3=$ strong complete membranous staining in more than $10 \%$ of tumour cells). Based on this score, the HER2/neu status was determined: Score 0-1 was considered negative, Scores 2 and 3 was considered positive.

\section{Differential expression of proteins with well-known difference in expression in IBC and non-IBC}

Previous studies showed a difference in protein expression for ER, PR, p53 and HER2/neu in IBC and non-IBC. Steroid hormone receptor status and score, HER2/neu status and score and p53 status (determined as described above) were compared in the TMA of IBC and non-IBC.

\section{Concordance between HER2/neu status determined using different antibodies}

We compared the expression of the HER2/ neu oncoprotein determined by the HercepTest (DakoCytomation, Glostrup, Denmark) with the expression of the HER2/neu oncoprotein determined using the TAB250 antibody, the CB11 antibody or a combination of both antibodies. The TAB250 and CB11 HER2/neu score and status were determined us- ing the same scoring system as the HercepTest. For the combination of the CB11 and TAB250 antibody, a doublescore and according status were calculated as described by Sapino et al. [21].

\section{Tissue loss}

To minimise tissue loss during microtome sectioning and tissue transfer, the TMA was incubated for $30 \mathrm{~min}$ at $40^{\circ} \mathrm{C}$ as described in the manual of the Beecher Instruments Tissue Arrayer (Beecher Instruments, Silver Springs, MD, USA). To evaluate the efficiency of this incubation, unstained microtome sections were evaluated macroscopically. The number of empty core biopsy positions was counted on five subsequent sections. To evaluate tissue loss caused by the aggressive pre-treatment of certain IHC staining procedures, the number of core biopsies and number of patients that could be evaluated (at least one core biopsy containing tumour cells left), was compared after different IHC staining procedures. The slides were divided into two groups, according to pre-treatment: one group without aggressive pre-treatment and one group with aggressive treatment $(30 \mathrm{~min}$ in warm water bath at $\left.98^{\circ} \mathrm{C}\right)$. 
IBC - patients ( 5 cores per patient)

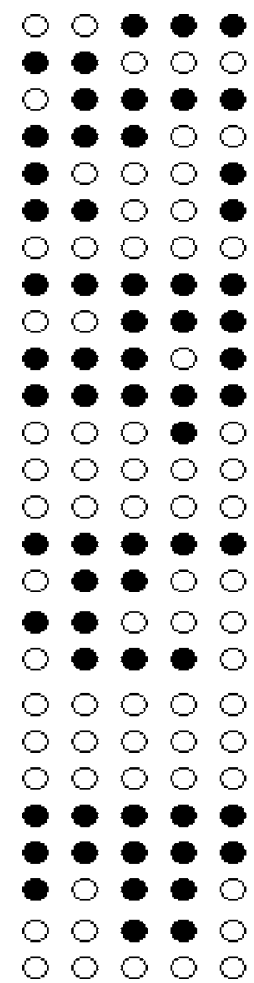

Column 1

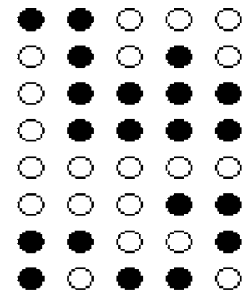

Column 2
Non-IBC - patients ( 3 cores per patient)

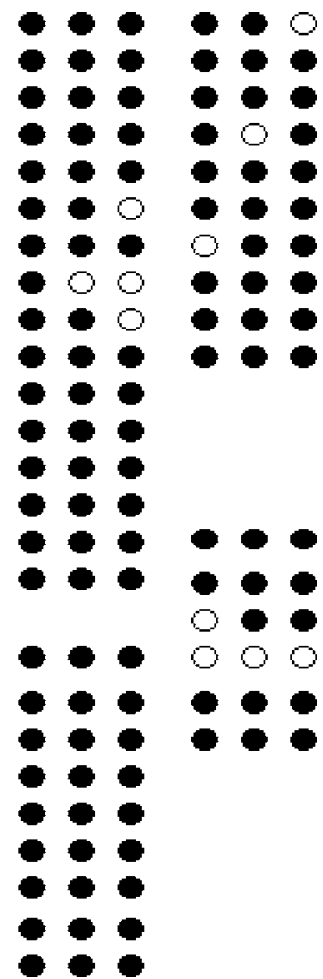

Column 3

Figure 2. Results of control haematoxylin-eosin slide of TMA. Black rounds represent informative core biopsies (core biopsies containing breast cancer cells), white rounds represent non-informative core biopsies (empty core biopsies or core biopsies not containing any cancer cells). Seventeen of $34(50 \%)$ IBC tumours and two of $41(4.9 \%)$ non-IBC tumours had more informative than non-informative core biopsies $(p<0.0001)$. In eight of $34(23.5 \%)$ IBC tumours all core biopsies were non-informative, compared to one of 41 non-IBC tumours $(2.4 \%)$ $(p<0.01)$.

\section{Differential protein expression}

Differential protein expression of CA IX, EGFR, RhoC and E-Cadherin in IBC and non-IBC was studied. For CA IX a semi-quantitative score was calculated by multiplying the $\%$ of immunoreactive cells with the intensity on a $0-3$ scale (score $0-300$ ). The immunoreactivity for EGFR was evaluated on a 0-3 scale using the same scoring system as the HercepTest (DakoCytomation, Glostrup, Denmark). The immunoreactivity for E-Cadherin was evaluated as described by Kleer et al. [15]. The interpretation of the staining for the RhoC GTPase antigen was done as described by Kleer and van Golen [16].

\section{Statistical analysis}

Statistical analysis was done with the SPSS package, version 11.0. Statistical significance was accepted at $p<0.05$. When describing the TMA, the presence of core biopsies was tested using a Chi-square test (or Fisher's exact test when necessary). For testing differential protein expression in IBC and non-IBC, a Chi-square test was used for status and a nonparametric Mann-Whitney $U$-test was used for scores. Concordance between two IHC staining procedures was studied with a Kappa test, using the criteria according to Landis [22].

For testing normal distribution of data, we used a Shapiro Wilk test. When data were normally distributed, comparison of means was done by an unpaired $T$-test.

\section{Results}

Description TMA

Figure 2 shows the presence and cancer cell content of all core biopsies as determined on a control 


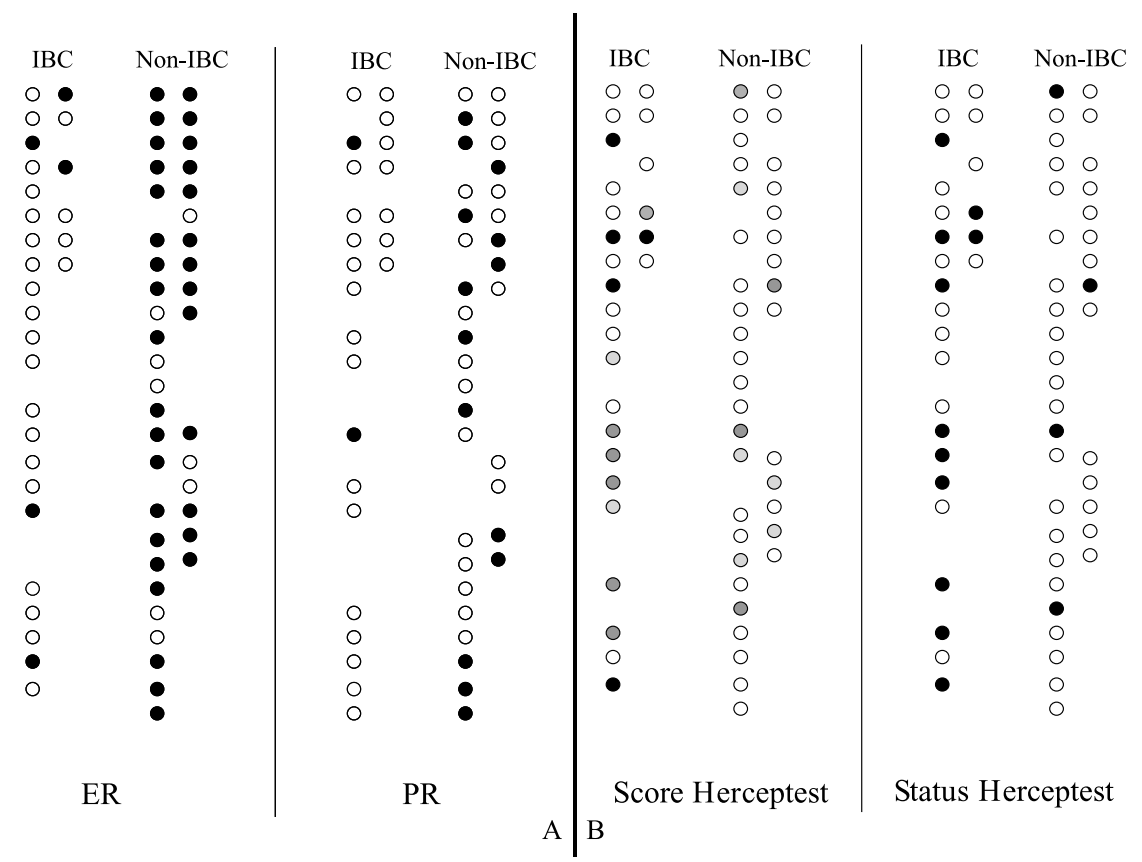

Figure 3. Differential expression of ER, PR and HER2/neu in IBC and non-IBC. (A) ER (left) and PR (right) expression is lower in IBC compared to non-IBC. A black round is a ER/PR positive tumour, a white round is a ER/PR negative tumour. 17.9 and $8.3 \%$ of IBC tumours are positive for ER and PR respectively compared to 80 and $41.2 \%$ of non-IBC $(p<0.01)$. (B) HER2/neu score (left) and status (right) are higher in IBC compared to non-IBC. Left: a black round is score 3, a dark grey round is score 2, a light grey round is score 1 and a white round is score 0; Right: a black round is HER2/neu positive, a white round is negative. $42.3 \%$ of IBC tumours were HER2/neu positive, compared to $10.8 \%$ of non-IBC tumours $\left(p_{\text {score }}=0.01 ; p_{\text {status }}=0.006\right)$. $(E R-$ estrogen receptor; PR - progesterone receptor; IBC - inflammatory breast cancer; HercepTest (DakoCytomation, Glostrup, Denmark).)

haematoxylin-eosin slide. In 17 of $34(50.0 \%)$ IBC tumours there were more non-informative cores (empty or not containing any cancer cells) than informative cores, compared to two of $41(4.9 \%)$ non-IBC patients $(p<0.0001)$. In eight of $34(23.5 \%)$ IBC tumours all cores were non-informative, compared to one of 41 non-IBC tumours $(2.4 \%)(p<0.01)$.

\section{Validation TMA}

Concordance between results of the pathology report and the TMA results

A good to excellent concordance between the TMA results of IHC analysis for ER, PR, HER2/neu and p53 and the results of the whole tissue section IHC analysis for these antigens was noted $\left(\kappa_{\mathrm{ER}}=0.74 ; \kappa_{\mathrm{PR}}=0.90\right.$; $\left.\kappa_{\mathrm{HER} 2 / \text { neu }}=0.85 ; \kappa_{\mathrm{p} 53}=0.50\right)$.

Differential expression of proteins with well-known difference in expression in IBC and non-IBC

The known differential expression of ER, PR, p53 and HER2/neu in IBC and non-IBC was confirmed on the
TMA. Figure 3 shows the results of IHC for the ER, PR and HER2/neu antigens. 17.9 and $8.3 \%$ of the IBC are positive for ER and PR respectively, compared to 80.0 and $41.2 \%$ for ER and PR in non-IBC $\left(E_{\text {score }}\right.$ $p<0.0001$ and $\mathrm{PR}_{\text {score }} p=0.002 ; \mathrm{ER}_{\text {status }} p<0.0001$ and $\mathrm{PR}_{\text {status }} p=0.007$ ). For $\mathrm{p} 53$, differential expression in IBC and non-IBC was also found: $30.8 \%$ of IBC tumours was p53 positive, compared to none of the non-IBC tumours $(p<0.001)$. HER2/neu, using

Table 2. Comparison of IHC HER2/neu status determined using HercepTest versus combination of the TAB250 and CB11 antibody. An excellent concordance was found $(\kappa=0.83)$

\begin{tabular}{cll}
\hline & \multicolumn{2}{c}{ Combination TAB250 $0^{\mathrm{b}}$ and CB11 ${ }^{\mathrm{c}}$ antibody } \\
\cline { 2 - 3 } & Negative & Positive \\
\hline HercepTest $^{\mathrm{a}}$ & & \\
Negative & 42 & 4 \\
Positive & - & 14 \\
\hline
\end{tabular}

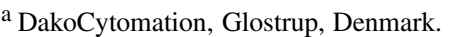

${ }^{\mathrm{b}}$ HER2/neu TAB250 antibody.

${ }^{\mathrm{c}}$ HER2/neu CB11 antibody. 
Table 3. Influence of pre-treatment of staining procedures on tissue loss of the TMA. Staining procedures are divided into two groups: one without pre-treatment and one with aggressive pre-treatment (warm water bath). The mean number of cores present after staining differs significantly between both groups $(p=0.015)$

\begin{tabular}{lllc}
\hline Pre-treatment & IHC staining & $\begin{array}{l}\text { Number of cores } \\
\text { present }\end{array}$ & \\
\hline None & Haematoxylin-eosin & 199 & Mean: $190.2 ;$ \\
& HER2/neu-TAB250 & 189 & SE: 2.87 \\
& HER2/neu-CB11 & 191 & \\
& EGFR & 191 & \\
& CA IX & 181 & Mean: $157.8 ;$ \\
& & 175 & SE: 10.14 \\
Warm water bath & PR & 182 & \\
\hline & ER & 140 & \\
& E-Cadherin 30 min $)$ & 163 & \\
& p53 & &
\end{tabular}

${ }^{\text {a } H E R 2 / n e u ~ I H C ~ s t a i n i n g ~ u s i n g ~ t h e ~ T A B 250 ~ a n t i b o d y . ~}$

${ }^{\mathrm{b}}$ HER2/neu IHC staining using the CB11 antibody.

${ }^{\mathrm{c}}$ EGFR.

Table 4. Differential protein expression in IBC and non-IBC as determined on our TMA

\begin{tabular}{lccc}
\hline & \multicolumn{2}{l}{$\begin{array}{l}\text { Protein expression \% positive patients } \\
\text { (exc E-Cadherin, CA IX and EGFR: median score) }\end{array}$} \\
\cline { 2 - 4 } & IBC & Non-IBC & $p$-value \\
\hline ER & 17.9 & 80.0 & $<0.001$ \\
PR & 8.3 & 41.2 & 0.007 \\
p53 & 30.8 & 0 & $<0.001$ \\
HER2/neu (HercepTest) & 42.3 & 10.8 & 0.006 \\
HER2/neu (TAB250 antibody) & 46.4 & 15.4 & 0.007 \\
HER2/neu (CB11 antibody) & 41.4 & 15.0 & 0.025 \\
HER2/neu (combi TAB250-CB11 antibody) & 50.0 & 17.5 & 0.005 \\
RhoC GTPase & 65.4 & 37.5 & $<0.001$ \\
E-Cadherin & 3.5 & 1 & $<0.001$ \\
CA IX & 0 & 0 & N.S. \\
EGFR & 0 & 0 & N.S. \\
\hline
\end{tabular}

the HercepTest, was significantly more expressed in IBC than in non-IBC. $42.3 \%$ of IBC tumours was HER2/neu positive compared to $10.8 \%$ of non-IBC tumours $\left(p_{\text {score }}=0.01 ; p_{\text {status }}=0.006\right)$.

\section{Concordance between HER2/neu status}

\section{as determined by using different antibodies}

An excellent concordance was found between the HER2/neu status determined using the HercepTest and the HER2/neu status determined using the CB11 antibody, TAB250 antibody and combination of both $(\kappa$ coëfficient respectively $0.86,0.78$ and 0.83 ). Table 2 shows the $2 \times 2$ table for HercepTest and the combination of the CB11 and TAB250 antibody.

\section{Tissue loss}

The number of empty core biopsy positions was counted macroscopically on five subsequent unstained slides. The average number of missing biopsies was 8.2 (range 7-9) or 2.8\% (range 2.4-3.1\%). After IHC staining, the number of biopsies was compared between two groups, one without and one with an 
aggressive pre-treatment. Table 3 shows the results. The mean number of biopsies left after IHC staining procedures was $190.2 \pm 2.87$ and $157.8 \pm 10.14$, for the groups without and with aggressive pre-treatment respectively ( $p=0.015$ ). The number of tumours that could be evaluated differed minimally but significantly: $62.6 \pm 1.29$ for staining procedures with aggressive pre-treatment versus $66 \pm 0.55$ for staining procedures without pre-treatment $(p=0.04)$.

\section{Differential protein expression}

A differential expression of RhoC GTPase and ECadherin in IBC and non-IBC was found: $65.4 \%$ of IBC patients was positive for RhoC GTPase, compared to $37.5 \%$ of non-IBC patients $\left(p_{\text {score }}=0.04\right.$; $\left.p_{\text {status }}<0.0001\right)$. The median E-Cadherin score for IBC was 3.5, compared to one for non-IBC $(p<0.001)$. For CA IX and EGFR no difference in expression was found on the TMA. Table 4 gives an overview of differential protein expression in IBC and non-IBC as determined on the TMA.

\section{Discussion}

We validate the use of our TMA for studying differential protein expression in IBC using three different approaches. This validation is necessary, because heterogeneous expression of certain proteins can lead to a sampling bias and misinterpretation of IHC reactivity on a TMA. Breast cancer is a morphologically and genetically heterogeneous malignancy [23-30]. IBC constitute a unique subtype of breast cancer with a characteristic infiltrative and diffuse growth pattern with small and separated tumour cell nests separated by tumour-related connective tissue stroma [1]. Furthermore patients with IBC are treated with neo-adjuvant chemotherapy before mastectomy, therefore availability of tissue taken before the start of neo-adjuvant chemotherapy is limited.

A very good to excellent concordance $(0.74<\kappa)$ between IHC results of whole tissue section examination and the TMA results was noted for ER, PR and HER2/neu. For p53 a good concordance $(0.40<\kappa)$ was found. Stabilisation of the p53 gene product is a heterogeneous phenomenon. Other authors found a better concordance when comparing TMAs and whole tissue sections in breast cancer [31, 32]. This is the first report of the construction of a TMA of IBC, and the concordance between IHC results of whole tissue sections and those of TMA has therefore never been studied before in this particular population. Camp et al. investigated in breast cancer how many core biopsies per patient are needed to reproduce IHC results of whole tissue sections on TMA for ER, PR and HER2/neu. They concluded that analysis of two cores is comparable to analysis of whole tissue sections in $95 \%$ of cases [33]. Because of the particular biology and diffuse growth pattern of IBC, we planned to include five core biopsies per IBC patient and three core biopsies per non-IBC patient to compensate for the sampling bias and tissue loss. Although five core biopsies per IBC patient were planned in our TMA, only half of the patients had three or more core biopsies containing tumour cells. Eight IBC patients did not have any core biopsy with tumour. Because of the diffuse growth pattern, the IBC core biopsies present contained less tumour compared to the core biopsies of non-IBC patients. More than five cores/patient might thus be necessary.

The most powerful validation for the use of the TMA for studying differential protein expression in IBC, was the confirmation of the known differences in expression of ER, PR, p53 and HER2/neu between IBC and non-IBC. The aim of the TMA technology is not to reproduce results of individual tumours but to show differences between large groups of tumours under standardised experimental conditions. IBC is a rare subtype of breast cancer. Our population is therefore substantial. Underestimation of expression due to tissue heterogeneity will not influence differential expression in different groups, when all groups are subjected to underestimation to the same extent. In our TMA this is not completely so: IBC has a diffuse growth pattern, therefore IBC cores contain less tumour tissue than non-IBC cores with often large areas containing only tumour-related stroma or incorporated normal breast tissue. The lower expression of ER and $\mathrm{PR}$ in IBC could be due to the underestimation of steroid hormone expression in IBC versus non-IBC. Nevertheless, steroid hormone receptors are relatively homogeneously expressed and differences have been shown before $[3,5,6,8,10,11]$. The possible underestimation of the expression of heterogeneously expressed proteins, such as mutated p53 and HER2/neu, in IBC makes the confirmation of the overexpression of the mutated p53 and the HER2/neu oncogen product in IBC even more significant [7, 9]. Differential expression for ER, PR, p53 and HER2/neu and the concordance between results for the HER2/neu status using three different antibodies (HercepTest, TAB250 
and $\mathrm{CB} 11$ ) has to be considered as a validation of the use of the TMA.

Another technical concern using TMA technology is tissue loss. Tissue core biopsies can be lost during microtome sectioning, tissue transfer and IHC staining procedures. In our study, the tissue loss during microtome sectioning and tissue transfer was minimal (2.80\%) even without using the Adhesive Tape System (Instrumedics Inc, Hackensack, NJ, USA). Incubation of our TMA for $30 \mathrm{~min}$ at $40^{\circ} \mathrm{C}$ is therefore a good method to minimise tissue loss. Tissue core biopsies were lost in IHC staining procedures with aggressive pre-treatment: $157.8 \pm 10.14$ biopsies left versus $190.2 \pm 2.87$ if no pre-treatment was done. Taking a higher number of core biopsies per patient might be necessary to minimise the loss of tumours/patients suitable for evaluation (no pre-treatment $66 \pm 0.55$ v.s. aggressive pre-treatment $62.6 \pm 1.29$ ).

Our TMA will primarily be used to validate results of gene microarray studies in IBC. A number of proteins, that are thought to play a role in IBC are studied in this paper. van Golen et al. described a role for RhoC GTPase in the IBC phenotype. Normal epithelial breast cancer cells transfected with RhoC GTPase show phenotypical aspects of IBC cell lines: they become more motile and invasive [34]. Recently, Kleer et al. found that expression of RhoC GTPase is present in a high proportion of primary IBC tumours and that it predicts the metastatic potential of invasive breast carcinomas smaller than $1 \mathrm{~cm}$ [16]. In the present study, we confirm the higher expression of RhoC GTPase in IBC. RhoC GTPase is also considered to play a role in the intense angiogenesis in IBC [35]. Our group previously showed that the increased angiogenesis in IBC is only partially hypoxia driven. On our TMA we do not find a difference in the expression of the hypoxia marker CA IX between IBC and non-IBC. Hypoxia can be a very local phenomenon, leading to very heterogeneous expression of CA IX. We confirm a higher expression of E-Cadherin in IBC. IBC seems to be an exception on the loss of ECadherin expression with dedifferentiation [36]. Kleer et al. and Colpaert et al. found that IBC tumours express high levels of E-Cadherin protein $[15,17]$. The cause of this overexpression is still uncertain. EGFR might be involved since stimulation of the EGFR by EGF and TGF- $\alpha$ results in a diminished expression of E-Cadherin [37]. Expression of the EGFR is associated with an invasive phenotype and worse prognosis [36]. Nevertheless, Guerin et al. showed that EGFR was less expressed in IBC [9]. We cannot confirm these findings on our TMA, this might suggest that these pathways are equally utilised in both types of breast cancer.

In conclusion we validated the TMA technology to study differential protein expression in IBC. Equal expression described by TMA technology for IBC and non-IBC can be caused by an equal phenotype for that protein or by a sampling-bias because of tissue heterogeneity. Our TMA will therefore be used for a first impression of the protein expression differences between IBC and non-IBC. It will be used in translational IBC research in our laboratory for confirmation of results of further experiments in general, and molecular biological experiments in particular, investigating the mechanisms causing the unique IBC phenotype.

\section{Acknowledgements}

Van den Eynden GG is a Research Assistant of the Fund for Scientific Research Flanders. This work was supported by FWO Flanders 'Kom op tegen Kanker', Grant No. G. 0330.02. and FWO 'Kredieten aan Navorsers' Grant No. 1.5.158.03. Furthermore we want to thank the technical staff of the laboratories of pathology from the University Hospital Antwerp and the AZ St. Augustinus.

\section{References}

1. Kleer GC, van Golen KL, Merajver SD: Molecular biology of breast cancer metastasis. Inflammatory breast cancer: clinical syndrome and molecular determinants. Breast Cancer Res 2: 423-429, 2000

2. Cristofanilli M, Buzdar AU, Hortobagyi GN: Update on the management of inflammatory breast cancer. Oncologist 8: 141-148, 2003

3. Koh EH, Buzdar AU, Ames FC, Singletary SE, McNeese MD, Frye D, Holmes FA, Fraschini G, Hug V, Theriault RL et al.: Inflammatory carcinoma of the breast: results of a combined-modality approach - M.D. Anderson Cancer Center experience. Cancer Chemother Pharmacol 27: 94-100, 1990

4. Jaiyesimi IA, Buzdar AU, Hortobagyi G: Inflammatory breast cancer: a review. J Clin Oncol 10: 1014-1024, 1992

5. Paradiso A, Tommasi S, Brandi M, Marzullo F, Simone G, Lorusso V, Mangia A, De Lena M: Cell kinetics and hormonal receptor status in inflammatory breast carcinoma. Comparison with locally advanced disease. Cancer 64: 1922-1927, 1989

6. Robertson JF, Ellis IO, Pearson D, Elston CW, Nicholson RI, Blamey RW: Biological factors of prognostic significance in locally advanced breast cancer. Breast Cancer Res Treat 29: 259-264, 1994

7. Turpin E, Bieche I, Bertheau P, Plassa LF, Lerebours F, de Roquancourt A, Olivi M, Espie M, Marty M, Lidereau R, 
Vidaud M, de The H: Increased incidence of ERBB2 overexpression and TP53 mutation in inflammatory breast cancer. Oncogene 21: 7593-7597, 2002

8. Kaufmann M: Review of known prognostic variables. Recent Results Cancer Res 140: 77-87, 1996

9. Guerin M, Gabillot M, Mathieu MC, Travagli JP, Spielmann $\mathrm{M}$, Andrieu N, Riou G: Structure and expression of cerbB-2 and EGF receptor genes in inflammatory and noninflammatory breast cancer: prognostic significance. Int J Cancer 43: 201-208, 1989

10. Charpin C, Bonnier P, Khouzami A, Vacheret H, Andrac L, Lavaut MN, Allasia C, Piana L: Inflammatory breast carcinoma: an immunohistochemical study using monoclonal anti-pHER-2/neu, pS2, cathepsin, ER and PR. Anticancer Res 12: 591-597, 1992

11. Hahnel R, Twaddle E: Estrogen receptors in human breast cancer. 1 . Methodology and characterization of receptors. Steroids 18: 653-680, 1971

12. Kleer CG, Zhang Y, Pan Q, van Golen KL, Wu ZF, Livant $\mathrm{D}$, Merajver SD: WISP3 is a novel tumor suppressor gene of inflammatory breast cancer. Oncogene 21: 3172-3180, 2002

13. van Golen KL, Davies S, Wu ZF, Wang Y, Bucana CD, Root H, Chandrasekharappa S, Strawderman M, Ethier SP, Merajver SD: A novel putative low-affinity insulin-like growth factorbinding protein, LIBC (lost in inflammatory breast cancer), and RhoC GTPase correlate with the inflammatory breast cancer phenotype. Clin Cancer Res 5: 2511-2519, 1999

14. Alpaugh ML, Tomlinson JS, Kasraeian S, Barsky SH: Cooperative role of E-cadherin and sialyl-Lewis X/A-deficient MUC1 in the passive dissemination of tumor emboli in inflammatory breast carcinoma. Oncogene 21: 3631-3643, 2002

15. Kleer CG, van Golen KL, Braun T, Merajver SD: Persistent E-cadherin expression in inflammatory breast cancer. Mod Pathol 14: 458-464, 2001

16. Kleer CG, van Golen KL, Zhang Y, Wu ZF, Rubin MA, Merajver SD: Characterization of RhoC expression in benign and malignant breast disease: a potential new marker for small breast carcinomas with metastatic ability. Am J Pathol 160: 579-584, 2002

17. Colpaert CG, Vermeulen PB, Benoy I, Soubry A, van Roy F, van Beest P, Goovaerts G, Dirix LY, van Dam P, Fox SB, Harris $\mathrm{AL}$, van Marck EA: Inflammatory breast cancer shows angiogenesis with high endothelial proliferation rate and strong E-cadherin expression. Br J Cancer 88: 718-725, 2003

18. Kononen J, Bubendorf L, Kallioniemi A, Barlund M, Schraml P, Leighton S, Torhorst J, Mihatsch MJ, Sauter G, Kallioniemi OP: Tissue microarrays for high-throughput molecular profiling of tumor specimens. Nat Med 4: 844-847, 1998

19. Sauter G, Mirlacher M: Tissue microarrays for predictive molecular pathology. J Clin Pathol 55: 575-576, 2002

20. Torhorst J, Bucher C, Kononen J, Haas P, Zuber M, Kochli OR, Mross F, Dieterich H, Moch H, Mihatsch M, Kallioniemi OP, Sauter G: Tissue microarrays for rapid linking of molecular changes to clinical endpoints. Am J Pathol 159: 2249-2256, 2001

21. Sapino A, Coccorullo Z, Cassoni P, Ghisolfi G, Gugliotta P, Bongiovanni M, Arisio R, Crafa P, Bussolati G: Which breast carcinomas need HER-2/neu gene study after immunohistochemical analysis? Results of combined use of antibodies against different c-erbB2 protein domains. Histopathology 43: 354-362, 2003
22. Landis JR, Koch GG: The measurement of observer agreement for categorical data. Biometrics 33: 159-174, 1977

23. Allred DC, Harvey JM, Berardo M, Clark GM: Prognostic and predictive factors in breast cancer by immunohistochemical analysis. Mod Pathol 11: 155-168, 1998

24. Bergers E, van Diest PJ, Baak JP: Tumour heterogeneity of DNA cell cycle variables in breast cancer measured by flow cytometry. J Clin Pathol 49: 931-937, 1996

25. Braun S, Hepp F, Sommer HL, Pantel K: Tumor-antigen heterogeneity of disseminated breast cancer cells: implications for immunotherapy of minimal residual disease. Int J Cancer 84: 1-5, 1999

26. Geyer H, Eberl M, Hornberger B: Influence of tissue heterogeneity on the determination of steroid receptors in breast cancer. J Cancer Res Clin Oncol 110: 141-144, 1985

27. Osborne CK: Heterogeneity in hormone receptor status in primary and metastatic breast cancer. Semin Oncol 12: 317-326, 1985

28. Paradiso A, Mangia A, Barletta A, Fusilli S, Marzullo F, Schittulli F, De Lena M: Heterogeneity of intratumour proliferative activity in primary breast cancer: biological and clinical aspects. Eur J Cancer 31A: 911-916, 1995

29. Poulsen HS, Jensen J, Hermansen C: Human breast cancer: heterogeneity of estrogen binding sites. Cancer 48: 1791-1793, 1981

30. Symmans WF, Liu J, Knowles DM, Inghirami G: Breast cancer heterogeneity: evaluation of clonality in primary and metastatic lesions. Hum Pathol 26: 210-216, 1995

31. Hoos A, Urist MJ, Stojadinovic A, Mastorides S, Dudas ME, Leung DH, Kuo D, Brennan MF, Lewis JJ, CordonCardo C: Validation of tissue microarrays for immunohistochemical profiling of cancer specimens using the example of human fibroblastic tumors. Am J Pathol 158: 1245-1251, 2001

32. Zhang D, Salto-Tellez M, Putti TC, Do E, Koay ES: Reliability of tissue microarrays in detecting protein expression and gene amplification in breast cancer. Mod Pathol 16: 79-85, 2003

33. Camp RL, Charette LA, Rimm DL: Validation of tissue microarray technology in breast carcinoma. Lab Invest 80 : 1943-1949, 2000

34. van Golen KL, Wu ZF, Qiao XT, Bao LW, Merajver SD: RhoC GTPase, a novel transforming oncogene for human mammary epithelial cells that partially recapitulates the inflammatory breast cancer phenotype. Cancer Res 60: 5832-5838, 2000

35. van Golen KL, Wu ZF, Qiao XT, Bao L, Merajver SD: RhoC GTPase overexpression modulates induction of angiogenic factors in breast cells. Neoplasia 2: 418-425, 2000

36. Beavon IR: Regulation of E-cadherin: does hypoxia initiate the metastatic cascade? Mol Pathol 52: 179-188, 1999

37. Beavon IR: The E-cadherin-catenin complex in tumour metastasis: structure, function and regulation. Eur J Cancer 36: 1607-1620, 2000

Address for offprints and correspondence: G.G. Van den Eynden, MD, Department of Pathology, Universiteit Antwerpen, Campus Drie Eiken, Universiteitsplein 1, B-2610 Antwerpen, Wilrijk, Belgium; Tel.: +32-3-443-36-37; Fax: +32-3-443-30-36; E-mail: gert.van.den.eynden@gvagroup.be 